\title{
Combining playware exergaming with a mobile fitness app
}

\author{
Emmanouil Giannisakis, Henrik Hautop Lund \\ Centre for Playware, Technical University of Denmark, 2800 Kgs. Lyngby, Denmark \\ hhl@playware.dtu.dk \\ www.playware.dk
}

\begin{abstract}
We propose a novel playware as a merge between exergames and mobile fitness apps to engage the users in physical exercises, not only as competitive play, but also in the form of cooperative play. The concept connects modular interactive tiles with radio communication to Android tablets and smart phones, which can connect to the Internet. This allows the players to monitor their playware exergaming performance on the smart device(s). A test was set up over 8 days allowing two school classes to compete with each other on which class was going to collect the most points playing on the modular tiles during the test. The test subjects were from 6th and 7th grade (12-13 years old children). As a social playware, we investigated how the playware mediated cooperative and competitive play amongst the users. It was found that the majority of game play involved social interaction between players, and that 8 out of 10 pupils on the top- 10 were girls. The playware seemed to motivate the girls to become physically active.
\end{abstract}

Keywords: Playware, Exergaming, Mobile App, Modular Technology, Cooperative Play, Gender, Social Playware.

\section{Introduction}

Exergaming has been a popular area of research and development in recent year, for instance resulting in games for health. Exergaming ("exercise" and "gaming") is fitness gaming where video games provide exercise, and it may often rely on technology that tracks body movement or reaction. Some exergames results from the research field of playware [1, 2], which has a core technology research activity focusing on research into modular playware technology and its supporting fundamental research areas of modern AI, adaptivity, modular robotics, and tangible interfaces. This is combined with a deep knowledge of play and play culture to create exergames that are fun, playful and motivating for the users to engage with out of their own free will and desire to play.

With the work presented here, we propose a novel playware as a merge between the exergames and mobile fitness apps to engage the users not only in competitive play, but also in cooperative play. We try to incorporate both competitive and cooperative play, since we hypothesize that this may attract both genders, especially also girls, to become physically active. Hence, we build a simple mobile app for smart devices on top of a playware tool (modular interactive tiles) - see Fig. 1 - with wellknown health benefits [3], and make a qualitative study of the effect of the competitive and cooperative social play that the mobile app adds to the playware tool.

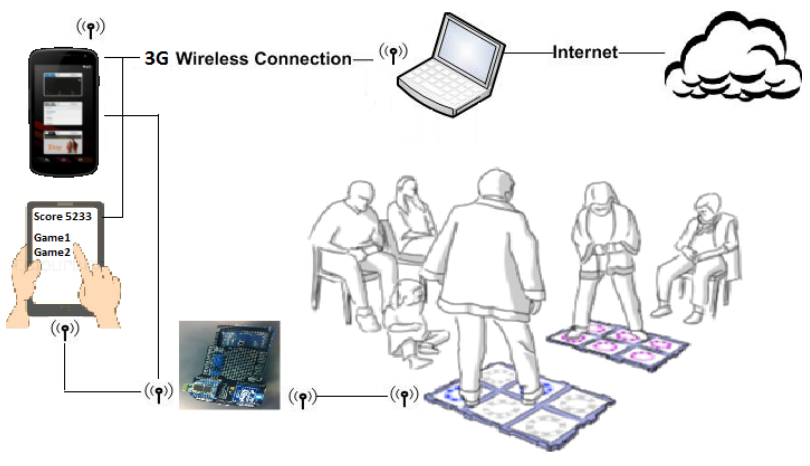

Figure 1: The concept connects modular interactive tiles with radio via a board with XBee and Bluetooth to Android tablets and smart phones, which can connect to the Internet (e.g. for storing database). Players can choose games and player IDs on the smart device(s) and monitor their performance on the smart device(s). 
A system of modular robotic tiles was developed $[4,5]$ and used extensively in physiotherapy and rehabilitation using this platform as a form of exergaming, e.g. [6]. The way the system works is that in the tiles different games can be programmed and the patients are performing physiotherapy exercises by playing these physical interactive games. A challenge for a system like the modular interactive tiles and other exergaming systems is how they can motivate the users to keep playing. Therefore we conducted a user testing in a school where pupils from two classes acted as testers in order to see if competition between the users, cooperation between the users, seeing the score from a game and seeing the score from the other players affected the motivation of the pupils to play.

\section{Mobile App For Smart Devices}

We developed a simple app to run on top of the modular interactive tiles to provide feedback to the users on a tablet (in a shared form) or a smart phone (privately). When a user is playing a game on the modular interactive tiles, the system can monitor different variables such as points, time, level, etc. These variables are provided to the mobile app, which can provide feedback to the user after the end of a game. The feedback provided to the user consists of the following attributes:

1. The points that the user got

2. The duration of the game

3. The number of misses

4. The level of difficulty

5. The winner of the game

6. The number of tiles that were used

Not all the attributes are relevant to every game. For example the winner attribute is not being used in one player games.

To simplify the setup of the experiment presented here, we used an Arduino Uno board to facilitate the communication between the tiles, which communicate with XBee, and the mobile device(s), which communicate with Bluetooth. To the Arduino Uno board, we attached a Bees shield with an Xbee radio module and a Bluetooth Bee module (see Fig. 2). The way we achieve communication is that the master tile communicates with the Xbee radio module of the Arduino board and the mobile device is connected with Bluetooth communication with the Bluetooth Bee (see Fig. 1). The Arduino Uno is responsible of receiving the messages from one radio module and properly forward and modify the received message to the other radio module. The tablet application sends messages that contain request for the tiles to change the game to another one, while the tiles send messages that contain the feedback of the game.

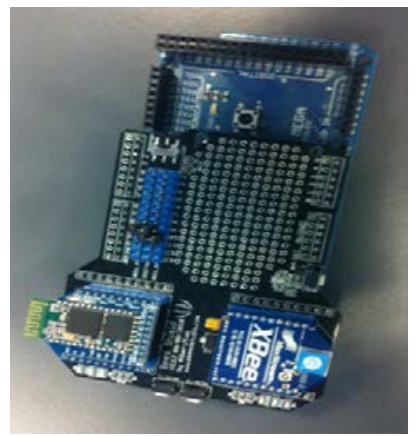

Figure 2. Arduino Uno with beeshielded Bluetooth and Xbee bee.

The mobile app was developed to run on Android devices. It was developed to be able to run on both Android tablets and Android smart phones. This application supports user creation, group creation and competition creation. In addition, it is connected with the modular interactive tiles so that the user can choose the game that the user wants to play and to receive and store the score from the game. With the tablet, more than one user can play a game, and in that case the score is divided by the number of users. The received score is being saved in a local database. Finally, the users have access to their current total score, the high score they have achieved for each game as well as the current total score and the high scores of the other players.

\section{User Testing Setup}

A test was set up over 8 days in the Oesterbro international school in Copenhagen, Denmark. The premise of the test was that two classes were going to compete with each other on which class was going to collect the most points during the test. For this purpose 6th and 7th grade (12-13 years old children) was chosen and they would compete with each other.

We provided the school with a set of 10 modular tiles (1 master and 9 normal), a tablet with the tablet application and the Arduino board with the Bees shield.

The pupils had the chance to play with the tiles during the breaks. The school had two break sessions: one from 09:35-09:55, and one from 11:45-12:05, i.e. two times 20 minutes per day. During those periods whoever of the participants who wanted to play could come, choose the 
desired game and the other participants that they wanted to play with (if they wanted to play with other people), and they would start playing. Hence, in total the pupils could play for 8 days $* 2 * 20$ minutes/day.

\section{Results}

Of the 33 active participants, 14 were male and 19 were female (i.e. $42.5 \%$ were male and $57.5 \%$ were female). On average, each of the 33 participants played 29.2 times and for 2.9 days. On average, each player played for 1171 seconds during the testing with the most active player to have played 4057 seconds. Out of the total 401 games that were played, 222 were played by groups of people. The groups that were formed were consisting of students of the same class. Table 1 shows the top 10 players of the high score list at the end of the test. It is noteworthy that from the ten players with the highest total score 8 were female and 2 were males (the number one player being male).

Table 1 . The top 10 players at the end of the experiment. $80 \%$ of the top 10 players were female.

\begin{tabular}{|c|c|c|c|c|}
\hline Player id & $\begin{array}{c}\text { Total } \\
\text { sore }\end{array}$ & $\begin{array}{c}\text { Total } \\
\text { duration }\end{array}$ & $\begin{array}{c}\text { Number of } \\
\text { games }\end{array}$ & Gender \\
\hline \hline 42 & 3934 & 2630 & 49 & Female \\
\hline 53 & 4645 & 3679 & 117 & Female \\
\hline 19 & 5016 & 2423 & 38 & Male \\
\hline 8 & 5112 & 2519 & 49 & Female \\
\hline 39 & 5403 & 2680 & 85 & Female \\
\hline 37 & 5419 & 3414 & 91 & Female \\
\hline 9 & 5589 & 2178 & 38 & Female \\
\hline 48 & 5989 & 2120 & 64 & Female \\
\hline 27 & 6087 & 4057 & 91 & Female \\
\hline 55 & 7520 & 3201 & 94 & Male \\
\hline
\end{tabular}

When looking more detailed at the play of the boys and the girls, there are some significant differences. Most notably, on average each participating girl played for a total of 1464 seconds, while each participating boy, on average, played for a total of 774 seconds. Hence, each girl would play almost double as much as each boy. Since the participants were free to come to the room to play whenever they wanted during the breaks during the 8 experiment days, it indicates that the girls were attracted more to the playware game than the boys.
As a qualitative evaluation of the test, a research assistant made observations during the intervention and made notes of these observations. Three cases were representative of the observations that were made during the experiment: the pupils would engage in

- Social, competitive play: groups would cooperate to achieve a higher group score than another group

- Social play to support individual competitive play: a group would form to help one individual to gain a higher score

- Individual competitive play: an individual would compete against herself or another individual on getting a higher score or reaching a specific goal

\section{Discussion}

Even if the collection and display of scores may seem to promote competitive play with focus on getting a higher score, the results showed that more than $55 \%$ of the use (222 out of 401 games played) was group play with social interaction between the players, and girls participated in $90 \%$ of these group plays. Even if the players tried to get a higher score, they did so in a cooperative manner in the majority of cases. This may be a contributing factor in explaining the relative high success amongst the girls (the girls were twice as active as the boys, and 8 out of 10 pupils on the top- 10 were girls), who may possibly enjoy the social, cooperative play. It is interesting that this playware motivated the girls to become so physically active.

We may speculate that the relative high success of this playware with the girls may be attributed partly to the facilitation of social, cooperative play in the competitive game scenario. The modularity of the modular interactive tiles facilitates social interaction by the physical layout of the modules, and the games are designed so that players can cooperate in the physical play. For instance, as more tiles are added to a platform of tiles, the more players can participate at the same time and cooperate to succeed in the game. One example is the Final Countdown game in which the user(s) has to keep the platform 'alive'. Each tile is counting down its LEDs, but all LEDs on the tile shine up again if the tile is being stepped on. If one tile in the whole platform goes to zero LEDs on, then the game is lost. The game can be played by one player, who will rush around on the tiles platform to keep all tiles alive, but a group of players soon discovers that they can help each other by each being in control of keeping a few of the tiles alive. So they distribute amongst each other the 
task of keeping the whole platform alive. Other games are designed in a similar fashion to allow social interaction and cooperation amongst the players.

Research in play, toys, computer games, and robotic games show that girls often tend to prefer cooperative play and boys tend to prefer competitive play, e.g. [7, 8, 9 , 10]. It is therefore also interesting, that with the physical interactive games, we can observe here that the facilitation of social, cooperative play within a competitive game scenario seem to attract the girls to engage in the play and to become physically active.

It suggests that the playware in this experiment becomes a mediator for playful social interaction. Indeed, social playware has been defined as playware which aims at creating playful social interaction between several users [11], see also [12]. With social playware, the starting point for the research and development becomes the social interaction mediated by the technology rather than the individual interaction mediated by the technology. In the present case, the results suggest that users - boys and girls - become physically active in a social way with social playware like the one which was carefully designed for the present experiment in the form of modular interactive tiles with a mobile app for both cooperative and competitive play.

\section{Acknowledgements}

The author would like to thank colleagues from the Center for Playware, DTU for collaboration, help and discussions related to the experiment presented here. Also, the authors would like to thank the participating children and teachers at Oesterbro International School, Denmark.

\section{References}

[1] H. H. Lund, T. Klitbo, and C. Jessen, C. "Playware Technology for Physically Activating Play”, Artificial Life and Robotics Journal, 9:4, 165-174, 2005.

[2] H. H. Lund, and P. Marti. "Designing Modular Robotic Playware”. In Proc. of 18th IEEE Int. Symposium on Robot and Human Interactive Communication (Ro-Man 2009), IEEE Press, 115-121, 2009.

[3] Lund, H. H., and Jessen, J. Effects of Short-Term Training of Community-Dwelling Elderly with Modular Interactive Tiles, Games for Health Journal, 3:5, 2014.
[4] Lund, H. H. "Modular Robotics for Playful Physiotherapy". In Proceedings of IEEE International Conference on Rehabilitation Robotics, IEEE Press, 571575, 2009.

[5] US Patent No: 8,241,183. "Modular robotic tiles for physical interaction”, 2012.

[6] Nielsen, C. B. and Lund, H. H. “Adapting Playware to Rehabilitation Practices”. International Journal of Computer Science in Sport, 11:1, 2012.

[7] Leaper, C. "Gender, affiliation, assertion, and the interactive context of parent-child play”. Developmental Psychology, 36, 381-393, 2000.

[8] Dawson, C., Cragg, A., Taylor, C., and Toombs, B. "Video games: research to improve understanding of what players enjoy about video games, and to explain their preferences for particular games". British Board of Film Classification, 2007.

[9] Lund, H. H. and L. Pagliarini, L. "LEGO Mindstorms Robot Soccer”. In Proceedings of RoboCup'98, LNAI 1604, Springer-Verlag, Heidelberg, 1999.

[10] Lund, H. H. “Adaptive Robotics in Entertainment”. Applied Soft Computing, 1:1, 2001.

[11] Lund, H. H. and T. Thorsteinsson, T. "Social playware for mediating teleplay interaction over distance". International Journal Artificial Life and Robotics, 16:4, 435-440, 2012.

[12] Suzuki, K. "Social Playware: Device-mediated social interaction for therapeutic activities." Robot and Human Interactive Communication, 2014 RO-MAN: The 23rd IEEE International Symposium on. IEEE, 2014. 